come under my observation, I have been led to present these thoughts for the consideration of this Section.

There must be a widely disseminated conviction of the truths upon which our Boards of Health are founded before we can hope to elevate the status of the health of our communities to the point which we desire. It must be strong enough to supplant the prejudices above alluded to, which have an abiding presence in the minds of the people; and this can only be effectually done by the means here suggested. I do not say that our Boards of Health have been failures ; on the contrary, they have been of great and inestimable value in educating the better part of our communities, and are gradually taking a deeper hold on their conscientiousness. So we must labor on, not relaxing anything already gained, as in all our efforts to bring up the people to a higher plane in any improvement of their condition, we constantly find great cause for discouragement where we expected sympathy and assistance. We need only to refer to the retrograde movement in Boston, when the efficient State Board of Health was disbanded, and the venerable Dr. Bowditch, with all his valuakle experience in hygienic matters, was supplanted, and the efficiency of the system embarrassed by that which was substituted.

The wisdom of our legislators does not always extend into the invisible; they can forecast a loss of political influence and power-or they think they can; though even here in their favorite haunts their wisdom sometimes proves to be folly - so when everything around seems quiet, and no pestilence threatens immediately, and death seents to have fled to some other sphere, they demur when you ask them to assist in executing plans for the prevention of disease, because they can't see the immediate propriety of such action. The enactment of a law on this subject brings no votes, and the rejection of it loses none; and hence they easily postpone the matter indefinitely. Why? Because constituents care about as little for the law as do their representatives. If the people were as well educated and impressed with the inestimable value of our subject as they should be, or as they are in regard to the value of their business affairs, there would be a different set of men, and a different course of legislation; and this subject, instead of being the last to be thought of, would take its proper place on the list of the legislative bills.

It is not my wish to advance any opinion upon the merits or demerits of the various books which have been produced as proper for the instruction in hygiene in our schools, except in a general way.

When the subject of physiology was first introduced into our higher schools, it was mainly confined to the scientific exposition of the structure and functions of the human body; leaving the application of the principles there set forth to the discrimination of the pupil, as circumstances might arise in the future. This was well as far as it went, and it was all that the times demanded; but in the present progressive stage of hygienic knowledge, it has become evident that this kind of exposition is insufficient. That class of books ought, therefore, to be discarded, and others possessing the proper requirements be substituted. There are such to be obtained, which set forth the laws of health, and which should be commended to school boards, should be heartily appreciated by the teacher, and should have no secondary place in the curriculum of studies. When this takes place, we may expect the next generation to be ready to uphold the hands of those who are endeavoring to forward this beneficent movement.

In advancing this cause there is no class of men who have more influence than physicians, and hence whenever that influence can be brought to bear upon our school directors, it is plainly our duty to exert it in whatever way seems most practicable for accomplishing the desired purpose.

\section{A CASE OF PAINFUL SUBCUTANEOUS NEUROMA (NEURO-FIBROMA).}

Read in the Section of Dermatology and Syphilography, at the Fortieth Annual Meeting of the American Medical Association, June, 1880 .

BY J. ABBOTT CANTRELL, M.D., OF PHILADELPHIA.

Jack C., 29 years oi age, was born, and has always lived, in New Jersey. $\mathrm{He}$ is a farmer by occupation, although obliged to retire temporarily at times, on account of the distress in the arms. His previous health was always excellent, and with the exception of a sister, his family have never presented a similar disease.

$\mathrm{He}$ noticed, for the first time, about fourteen years ago, a small round nodule on the left arm, accompanied with intolerable itching, but without pain. This nodule increased in size, slowly but steadily, reaching its present dimensions in about four years, by which time there four new and smaller lesions in the same vicinity. In eight years after the appearance of the first nodule a solitary lesion was noticed on the right arm correspondingly, which in four years was accompanied by five others. The man does not know exactly when the pain first began, but believes it was between four and five years after the appearance of the first tubercle.

This man presented himself for treatment at the clinic in April, r889, showing the lesions on both arms about midway between the tip of the shoulder and a point corresponding to the insertion of the deltoid muscle, being grouped on each arm, those on the left arm being five in number, the larger occupying the centre of the group, 
and being the size of a pea, while the others surrounding it were about the size of a pin's head.

Those on the right arm were similar in size, but there were five surrounding the central figure. The lesions are separated, one from the other, by about 5 or 6 lines. They are firmly situated in the skin and movable only with it. They certainly must run down into the subcutaneous tissue. They are elevated between 2 and 5 lines above the surrounding skin; the skin covering them is tightly drawn, being very smooth and shining brightly. The epithelium seems intact. The skin over the top of the larger lesions is of a yellowish pink, while at the base it is almost a purple; the smaller lesions are normal at the base but yellowish at the summit. All the lesions are perfectly round, the larger one looking as if a pea had been placed under the cuticle and was holding it out beyond the surrounding skin.

Surrounding the lesions the skin looked entire1y healthy, there not being a single dilated capillary visible, as tnight have been expected.

At the appearance, and during the continuance of the pains, there was no change of color, although the part became warmer than usual, remaining so for a short time after its subsidence. Cold and heat, from what I could learn, did not affect him in the least, but if slightly touched a great amount of pain was experienced. There is sturely a deep connection with a branch of the brachial plexus.

The pains, for which trouble he applied for treatment, were of a paroxysmal nature, and constituted the whole distress. They began by appearing slowly about four years after the appearance of the first tubercle and got worse as the disease progressed. I did not see him in any of the paroxysms, but from what he says I could readily imagine the greatest torture. The pains at times resembled an aching tooth, beginning with a throbbing sensation, and getting gradually worse, at last giving several great jumps almost causing him to fall to the floor. These pains lasted. from fifteen minutes to one-half hour, but were quite frequent during the day, and always worse at night, which only happened once or twice a week. The friction of his wearing apparel kept up a continual pain throughout the day, and at night the bedclothes could not be borne on the arms. When suffering from the worst pains he is oblivious to what is transpiring around him. If perchance the lesions be violently struck, or the arm be given a sudden jerk, the spot feels as if a sharp pointed instrument had been inserted, almost causing syncope, while the pain would last several hours; in fact, sometimes lasting all through the day-causing him to be constantly on the move and trying to forget it by the best possible means. If the lesions are handled slightly, as when examined, there is considerable pain.

He says he dislikes to go to bed on account of not being able to lie on either side, and fearing to lie on his back, lest in a moment of restlessness he may turn over on either arm, and be awakened suddenly as if he had been struck a sudden blow, so on account of this, when the pains were at their worst he occupied a large armchair and a footstool.

The day preceding a storm he feels very restless and uncomfortable, but on the appearance of the storm he is no worse. He feels very comfortable in settled weather, be it warm or cold.

In a careful search of the literature of the subject, I was only able to find four cases that present any similarity to the case of to-day-those of Dubring, Kosinski, John Ashhurst, Jr. and Jonathan Hutchinson, Jr. Most of the other and previous cases I feel are examples of the "painful subcutaneous tubercle.'

Duhring's case, a man 70 years of age, first noticed the disease ten years previously; it occupied the left scapular region, shoulder, and the outer side of the left arm as far down as the elbow, completely covering these parts.

Kosinski observed it in a man 30 years of age, who noticed it for the first time when 16 years of age, when it occupied the posterior and outer side of the right thigh, as far down as the lower third, and a portion of the buttock. There were as many as a hundred lesions.

In I 883 John Ashhurst, Jr., amputated the thigh between the middle and lower third. The flaps sloughing, a reamputation was necessary. Within a year, a small lump, tender to the touch, appeared in the skin, posteriorly and a little to the outer side of the stump.

Jonathan Hutchinson, Jr., reports a neuroma of the parotid in a girl 20 years of age.

I had hoped to-day to show microscopical sections of my case, but the man proving obstinate, would not allow me the privilege, so I will make the best of the bargain by giving the microscopical reports of the other cases, and show by them the fibroid nature of all these cases.

That of Duhring showed the "corium to be infiltrated with a new connective growth, which was firm in structure. The tissue, beneath and in the mass of the specimen, consisted of a solid, resistant-looking connective tissue, irregularly developed and uneven in arrangement. The bulk of the tissue was old in appearance and fitted together, the new cell elements being entirely wanting, the connective tissue fibrils being closely packed in places, forming wave-like bands. There were also numerous free fibrils of elastic tissue scattered here and there, and there were no nerve trunks or branches found in the mass."

In Kosinski's case, "the mass showed a consistence of gray nerve fibrils with a great quantity of a dense fibrous tissue, interspersed with some connective tissue."

Ashhurst found "interiorly in the tumor a somewhat elastic, rather dense-looking growth of 
whitish color, over which passed yellowish fibres, probably strands of the scaled nerve. Microscopically the interior showed an entire absence of nervous elements and a section exhibited fat cells, abundant fibrous tissue, some spindle cells and numerous free nuclei near the enlarged and dilated blood-vessels."

Hutchinson came to the conclusion, after a very exhaustive examination, that his case was undoubtedly of a fibroid nature, while it consisted of connective and a quantity of fibrous tissues.

With a summary of these four cases, all of which showed in their microscopical examinations a structure consisting of fibrous and connective tisstues, resembling those of the human body, also all sections of heretofore examined fibromatous tumors, I cannot but feel that to place them with the fibromata would certainly be to place them where they belong-calling them neuro-fibromata.

\section{A CASE OF ACUTE RHEUMATIC LARYN} GITIS OF GONORRHCEAL ORIGIN.

Read in the Section of Laryngology and Otology, at the Fortieth An nual Meeting of the American Medical Cssociation. June, j889.

BY W. K. SIMPSON, M.D., OF NEW YORK.

I present the following history on account of the apparent rarity of the case, and in so doing hope to add somewhat to the meagre literature of the subject. In the perusal of recent literature, and the reports of various throat clinics, and from inquiry among medical friends, I have been unable to find any reference to a similar case, thus convincing me that it is in some respects unique, and that the involvement of the larynx in acute gonorrhœal rheumatism is an extremely rare occurrence.

Sigimund H., æt. 23, single ; Poland; cigarette maker; was first seen by me on February 23, I888, at which time these notes were taken. He has had three attacks of gonorrhœea, the last one being five weeks ago; there is some urethral discharge at present. Three weeks ago he complained of pain and stiffness in the left knee, which shifted to the right knee, and then to the left hip, rendering locomotion very painful. Three days ago pain and swelling began in the left thumb, extending to the anterior surface of the wrist and back of the hand; and at the present time these parts present the typical swollen appearance of acute rheumatic inflammation.

The throat symptoms began three days ago, in the morning, with painful deglutition; and on the following morning there was a swelling over the lower external portion of the larynx, which swelling, at present, has disappeared. The swelling was very painful on pressure, especially on the right side. In the evening the patient be- came hoarse, and any attempt at talking was very painful.

Examination of the throat to-day reveals painful deglutition; pain on pressure over the right side of the larynx; almost entire loss of voice ; no cough. Internally, both arytenoids are swollen and red, the right one much more than the left, being also slightly odematous, resembling tubercular laryngitis, and is, along with the right vocal band, immobile on phonation. The whole of the mucous membrane of the interior of the larynx is hyperæmic, the left vocal band being slightly injected, while the right vocal band is swollen and of a deep purple color.

Treatment consisted in placing the patient on sodium salicylate, gr. xv every two hours, and applying a saturated solution of sodium bicarbonate to the wrist-joint.

From Feb. 23 to 28 there was no improvement in the throat symptonis; swelling was increasing and breathing was becoming embarrassed. On Feb. 28 iodide of potash internally was substituted, and on Feb. 29 a blister was applied over the right side of the larynx, which caused improvement in the laryngeal swelling. This improvement continued, and on March 6 the swelling was entirely reduced, and the voice was very much improved; but there was still very little motion of the right arytenoid and right vocal band, and the color of both was still very red.

\section{MEDICAL PROGRESS.}

TrEatMenT OF ERYSIPELAS by ANTISEPTICS. $-M$. JORISSENNE finds that in erysipelas the streptococci are so deeply seated that it becomes necessary to employ fatty substances as excipients in order to secure more prolonged contact of the remedies employed. For this purpose lanoline is unsuitable because it increases friction; vaseline prevents absorption; lard increases cutaneous irritation. The reporter therefore employs a mixture of cacao butter and vaseline as a suitable and convenient excipient. The most reliable antiseptic is sublimate, with which the reporter has achieved constant success in the erysipelas of the head occurring in newborn babes and complicating meningitis, as well as in the gangrenous erysipelas affecting the scrotum of old men, and in adults generally.-Le Bulletin Médical.

TREATMEN' OF GASTRIC NEURASTHENIA.In the treatment of dilatation of the stomach, according to DUJARDIN-BEAUMETZ, there are two principal indications: the one is addressed to the gastro-intestinal disturbances, the other to the condition of the nervous system. To fulfil the first of these indications there are two plans of treatment: the first comprises intestinal antisep- 